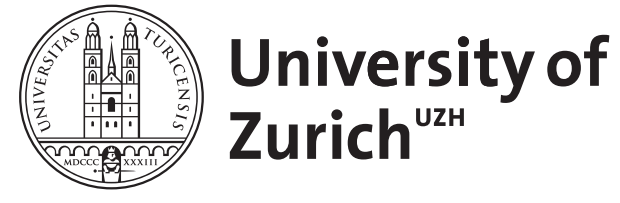
Archive

University of Zurich

University Library

Strickhofstrasse 39

CH-8057 Zurich

www.zora.uzh.ch

Year: 2013

\title{
Iron supplementation in pregnancy
}

Krafft, Alexander

DOI: https://doi.org/10.1136/bmj.f4399

Posted at the Zurich Open Repository and Archive, University of Zurich

ZORA URL: https://doi.org/10.5167/uzh-87059

Journal Article

Published Version

Originally published at:

Krafft, Alexander (2013). Iron supplementation in pregnancy. BMJ : British medical journal, 347 :f4399.

DOI: https://doi.org/10.1136/bmj.f4399 


\title{
Iron supplementation in pregnancy
}

\author{
At last, benefits on maternal measures and risk of low birth weight are shown
}

\author{
Alexander Krafft consultant \\ Division of Obstetrics, Department of Obstetrics and Gynecology, University Hospital Zurich, CH 8091 Zurich, Switzerland
}

In the linked review and meta-analysis of anaemia, prenatal iron use, and the risk of adverse pregnancy outcomes (doi:10.1136/ bmj.f3443), Haider and colleagues make a strong case for iron supplementation in pregnancy. Iron deficiency is the world's most common and widespread nutritional disorder. Not only does it affect many women and children in developing countries, it is the one nutritional deficiency that is also highly prevalent in industrialised countries. World Health Organization data indicate that a staggering two billion people-around $30 \%$ of the world's population-may have anaemia, mainly as a result of iron deficiency, often exacerbated in resource poor areas by infectious disease. ${ }^{2}$ Iron deficiency is thus an important health problem worldwide.

Pregnant women, and women of childbearing age in general, are in particular need of iron supplementation. Even under optimal dietary conditions, daily intestinal absorption cannot meet the pregnancy requirement of 1-1.2 g iron. ${ }^{3}$ But curiously the case for iron supplementation remained unconfirmed after Cochrane reviews and other meta-analyses concluded that iron supplementation prevented maternal anaemia and iron deficiency at term but was not beneficial (or harmful) in terms of neonatal outcome (such as low birth weight, delayed development, preterm birth, infection). ${ }^{4-6}$

Haider and colleagues comprehensively reviewed the evidence from randomised trials and prospective cohort studies for an association between anaemia, iron use in pregnancy, and maternal and pregnancy outcomes. They concluded that daily prenatal oral iron significantly reduced maternal anaemia, iron deficiency, iron deficiency anaemia, and the risk of low birth weight, but that the reduction in the risk of preterm birth was not significant. ${ }^{1}$

Guidelines, prevention and treatment programmes, and expert recommendations regarding the dose and route of daily iron supplementation in pregnancy are conflicting. ${ }^{7}$ However, the dose-response analysis by Haider and colleagues categorically shows a linear decrease in maternal anaemia with increasing iron doses up to $66 \mathrm{mg}$ per day, which approximates to the WHO standard treatment of $60 \mathrm{mg}$ per day. ${ }^{8}$ Increasing iron doses are associated with linear increases in prenatal mean haemoglobin and birth weight, hence with decreased risk of low birth weight.
The causes of preterm birth are complex and multifactorial; they include infection, inflammation, vascular disease, and stress. ${ }^{9}$ Finding a straight correlation between iron supplementation and a reduction in preterm births was thus as unlikely in principle as the philosopher's stone. However, meta-analysis of the cohort studies identified a higher risk of preterm birth in women with anaemia in the first or second trimester and lower mean haemoglobin. This finding adds to our understanding of the complex causes of preterm birth and modulates the multifactorial approach needed for prevention.

Although not a primary focus of the analysis, the increase in mean maternal haemoglobin is likely to lower the risks of severe postpartum anaemia and the need for transfusion in many young and otherwise healthy women. This should equate indirectly to a reduction in morbidity and mortality, whether perinatal and neonatal or maternal, thanks to the simple measure of taking one iron tablet a day during pregnancy.

The only flaw in Haider and colleagues' study is that it has come fractionally too late to claim the pride of place it deserves. After long years of looking for better evidence favouring iron supplementation in pregnancy, the Cochrane review was updated in December 2012. ${ }^{10}$ Its revised conclusions anticipated those that Haider and colleagues have now masterfully and comprehensively confirmed.

Competing interests: I have read and understood the BMJ policy on declaration of interests and declare the following interests: None. Provenance and peer review: Commissioned; not externally peer reviewed.

1 Haider B, Olofin I, Wang M, Spiegelman D, Ezzati M, Fawzi WW. Anaemia, prenatal iron use, and risk of adverse pregnancy outcomes: systematic review and meta-analysis. BMJ 2013;346: $\{3443$.

2 WHO. Micronutrient deficiencies: iron deficiency anaemia. 2013. www.who.int/nutrition/ topics/ida/en/.

3 Milman N. Iron and pregnancy-a delicate balance. Ann Hematol 2006;85:559-65.

4 Pena-Rosas JP, Viteri FE. Effects and safety of preventive oral iron or iron+folic acid supplementation for women during pregnancy. Cochrane Database Syst Rev 2009;4:CD004736.

5 Beaton G. Efficacy of intermittent iron supplementation in the control of iron deficiency anaemia in developing countries. An analysis of experience. 1999. http://idl-bnc.idrc.ca/ dspace/bitstream/10625/29662/3/117067.pdf.

6 Beaton G. Iron needs during pregnancy: do we need to rethink our targets? Am J Clin Nutr 2000;72(suppl):265S-71S.

7 Milman N. Prepartum anaemia: prevention and treatment. Ann Hematol 2008;87:949-59. 
8 WHO. Iron and folate supplementation. Standards for maternal and neonatal care. Integrated management of pregnancy and childbirth (IMPAC). Department of Making Pregnancy Safer, 2007. http://whqlibdoc.who.int/hq/2007/a91272.pdf.

9 Goldenberg RL, Culhane JF, lams JD, Romero R. Epidemiology and causes of preterm birth. Lancet 2008;371:75-84
10 Pena-Rosas JP, De-Regil LM, Dowswell T, Viteri FE. Daily oral iron supplementation during pregnancy. Cochrane Database Syst Rev 2012;12:CD004736.

Cite this as: BMJ 2013;347:f4399

(c) BMJ Publishing Group Ltd 2013 